Ali Shiri

School of Library and Information Studies, University of Alberta, Edmonton, Alberta, Canada

Deanna Lyn Howard

School of Library and Information Studies, University of Alberta, Edmonton, Alberta, Canada

Sharon Farnel

University of Alberta Libraries, Edmonton, Alberta, Canada

\title{
Indigenous Digital Storytelling for Cultural Heritage Access and Preservation (Paper)
}

\section{Acknowledgement}

As researchers at the University of Alberta, we acknowledge that we are located on Treaty 6 territory, and respect the histories, languages, and cultures of First Nations, Métis, Inuit, and all First Peoples of Canada, whose presence continues to enrich our vibrant community. We would particularly like to acknowledge our collaborative partners from the Paulatuk, Ulukhaktok, Sachs Harbour, Tuktoyaktuk, Inuvik, and Aklavik communities of the Inuvialuit Settlement Region (ISR) in the Northwest Territories.

\section{Abstract or Résumé:}

This paper reports on an examination and analysis of digital storytelling interface features and functionalities within a select number of Indigenous digital libraries and archives to support and inform the participatory and culturally-informed design and development of a digital storytelling system for the Inuvialuit Settlement Region in the Western Arctic. The paper presents participatory and inclusive design ideas and examples from Canada, US, and Australia.

\section{Introduction}

Indigenous communities around the world have been taking up digital media in their broader struggles for decolonization, self-representation, and self-determination (Ginsburg, 2016; O’Sullivan, 2013). Their histories have long been excluded or misconstrued in institutionalized settings and have thus been taken to the grassroots, community level for autonomous documentation (Flinn, Stevens, \& Shepherd, 2009). Flinn et al. (2009) assert that 
"histories, in particular public histories, are spaces of challenge and often bitter contestation" (p. 83). Thus through digital media projects, Indigenous peoples have fostered a sense of community resistance to and power against dominant colonial narratives, and a sense of control over collective memory (Flinn et al., 2009, p. 82). The histories shaped through these projects, even in their movement into the contemporary digital world, continue to be rooted in Indigenous traditions. These digital media projects enable social connections across different and distant geographies (Scales, Burke, Dallwitz, Lowish, \& Mann, 2013; Hamel, Benyoucef, \& Kuziemsky, 2012; Hopkins, 2006), Indigenous ways of knowing and sharing (Ginsburg, 2016; Christen, 2015b), language and cultural retention (Nakata, 2007; Cushman, 2013; Perley, O’Donnell, George, Beaton, \& Peter-Paul, 2016), and collaborative content creation (OrmondParker \& Slogget, 2012; Christen, 2011; Burgess, Klaebe, \& McWilliam, 2010). As “creators and innovators...of new technologies...[i]n the English-dominant world of cyberspace, Indigenous communities are engaging with, disrupting, and reimagining digital practices. By generating digital visibility and legibility, Indigenous communities claim a presence online and exert control over the terms of Indigenous representation rather than risk misrepresentation" (Brown, Carpenter, Lawson, Lawson, Nathan, \& Turin, 2017, p. 268). To this end, there has been a trend amongst Indigenous digital platforms towards integrating storytelling practices for a more dynamic, holistic approach to memory and history-making. Beyond just opening up collections, Christen (2015b) argues that these digital platforms are redefining traditional museum relationships amongst viewers, creators, and contributors (p. 384).

\section{Purpose Statement}

The research project is aware of the Inuit Tapiriit Kanatami (ITK) and has been closely following the key principles outlined in the National Inuit Strategy on Research (NISR). We have been consulting and seeking advice from the Inuvialuit Regional Corporation and several community organizations. The Aurora Research Institute (ARI) in accordance with the Northwest Territories Scientists Act and Administration Regulations. The ARI, IRC, Inuvialuit LandAdministration, and Environmental Impact Screening Committee (EISC) have developed a streamlined process to help researchers obtain the required permits and licenses to conduct research in the ISR. Researchers must also consult with and gain approval from the appropriate community organizations before the final Aurora Research Institute Scientific Research Licence is issued. We have been licensed to conduct research in the region in the past 7 years.

This project builds on and continues strong and positive relationships and collaborations with our community partners from six communities in the ISR: Paulatuk, Ulukhaktok, Sachs Harbour, Tuktoyaktuk, Inuvik and Aklavik.This project aims to build new audio-recording digital technologies based on the valuable feedback received from the ISR Inuit communities in numerous digital library workshops held in 2016 and 2017 in Inuvik, Aklavik, Sachs Harbour, Ulukhaktok and Paulatuk. The research compiled here is part of a larger project that aims to develop an interactive and real time digital storytelling system that will allow Inuit communities 
to enhance and preserve their cultural heritage, including the Inuvialuktun language and its three dialects. This paper specifically aims to report the results of a study that investigated and analyzed a select number of Indigenous digital archives and digital storytelling user interfaces in order to identify key features and functionalities that support the development of a digital storytelling system for the Inuit communities of the ISR. It will report on specific Indigenous digital cultural heritage collections with oral history content as well as specific culturallyinformed practices of user interface design. The focus of the project was to identify as many Indigenous digital storytelling systems as possible. This does not imply that the identified examples are particularly representative of all Indigenous communities or that in all of those digital projects Indigenous communities have been closely involved. Our focus has mainly been on the examples available on the web and in academic and cultural organizations. It is beyond the scope of this project to conduct a large scale survey of Indigenous communities' views on the identified digital platforms.

Additionally, because our goal is to provide a free and open access digital system and user interface that can be improved, modified, and updated by the community itself rather than requiring support from companies and IT corporations, we have focused our attention on noncommercial projects. While we acknowledge that requirements in every given context will be different, in general, commercial systems tend to be proprietary and require a lot of resources to maintain. Concerns about commercial systems have often been expressed in projects we have explored, and indeed in our own experience. For this reason, non-commercial has been a key characteristic in researching digital storytelling systems.

\section{Context and review of prior research}

\section{Digital Archives}

The archival profession has been recognizing the place of memory, tradition, and evidence for Indigenous communities in building collections (Nakata, 2007). Withey (2011) notes how the archival imagination has taken on new forms that re-evaluate the relationship between archives, official record keeping and nation building, as the colonial archive played an essential role in the elimination of Indigenous peoples. This recent imagination recognizes the political maneuverability involved in deploying and building archives (Withey, 2011, p. 118). These new archival forms challenge the open access and distribution of all digital materials, Western intellectual property systems and the exclusivity of traditional archiving practices, enabling Indigenous people to organize and describe their own collections (Christen, 2015a). This report examines how, in this new trajectory, digital archives have been developing novel features, such as crowdsourcing and user-submitted content, for more interactivity and collaboration amongst users (Thorner, 2010; Webb, 2015; Cook, 2013; Christen, 2011), as well as how content creation in two two major knowledge management platforms, Ara Iritja and Mukurtu, is based on cultural protocols. 


\section{Indigenous Oral Traditions}

Even with the upsurge of digital technologies and new modes of communication, storytelling has continued to be an essential method for sharing information and knowledge (Lawrence \& Paige, 2016). Storytelling, throughout history, has facilitated learning and teaching, the exploration of alternate realities, meaning-making, and the preservation of culture (Lawrence \& Paige, 2016; Thomas, 2005). Furthermore, storytelling today has become both a tool of resistance and an opportunity to go back in time (Thomas, 2005, p. 252; Corntassel, Chaw-winis, \& T'lakwadzi, 2009).

\section{Digital Storytelling}

Digital storytelling has been recognized as an important community and cultural practice since the 1990s, heavily revolving around the work of the Centre for Digital Storytelling, known today as StoryCenter (Lambert, 2013). The general process of digital storytelling today involves creating a personal narrative from a variety of media, such as images, audio, video, and text, in a workshop setting. These narratives are then shared in a public setting to demonstrate the similarities and diversity of these collective experiences (Willox et al., 2013). This report includes details about a variety of digital projects as well as the specific features and metadata that project coordinators have implemented for audio and video resources. It also considers ways that Indigenous communities across North America and in Australia are creating and using digital archives, new media projects, language databases, and existing digital platforms in community-oriented environments, as well as how the projects and platforms integrate oral communication and community participation in digital environments.

\section{Methodology}

As a whole, the project is informed by Indigenous and community-based research methodologies. Furthermore, the iterative development of an interactive storytelling system will adopt the participatory design methodology. The investigation and analysis of a number of Indigenous digital archives and storytelling user interfaces, which is the focus of this paper, will enhance and underpin the future participatory design process. Technology provides opportunities for communities to preserve and pass on their traditional knowledge and stories in their own way and according to their own protocols (Christie, 2005; Eagles, Woodward, \& Pope, 2005; Nakata, 2007). In order to create and develop a digital user interface with storytelling and commenting functionalities in collaboration with Inuit communities, we first conducted a comprehensive examination of existing Indigenous digital library and storytelling examples, and then looked at five in greater detail. It is not our suggestion that all Indigenous projects belong together simply 
because they are Indigenous, rather the five cases were selected because they demonstrate the variety of unique ways different communities have approached and utilized technology in different ways to share and preserve their own distinct languages, cultures, and histories. After investigating the background and details of each project, the five were selected for a closer analysis of how each project has designed audio and video recording user interfaces with storytelling and commenting functionalities, as well as how key information is captured in the metadata for each resource. The five projects are Voices of Amiskwaciy, Storylines, the Plateau Peoples' Web Portal, InuitQ Interactive Adventure, and the Dharug and Dharawal Resources collection. The projects chosen were participatory and culturally-informed design projects. The Inuvialuit Voices project is informed by Indigneous and community-based research methodologies including community consultation, participatory prototype design, and usability evaluation, and so in compiling the research for this paper we looked for projects that were developed under similar methodologies. The details for each project, including the communities and location, collaborators, content management platform, organization of resources, features, year, status, and statement of commitment, were collated in a table format. Additionally, the methods employed by each project for the organization of individual resources, including the URL, audio or video functionalities, file type, metadata fields, and traditional knowledge labels, were also assembled. Community partners will be involved to choose what interface elements are appropriate for the Inuvialuit Voices project. The initial prototype developed has basic design and the goal is to hold open house events in the region to engage community members in the design process.

\section{Analysis and findings: Digital Storytelling in Indigenous Digital Archives}

In this section, we briefly present an example of our analysis of Indigenous Digital Storytelling features and functionalities. Further details along with comparative examples will be provided in the presentation as we continue finishing and categorizing our findings. Examples of Indigenous digital archives reveal that interactivity, user-tagging, annotating, and giving users the opportunity to add audio comments are among the features that enable collaboration. With community control and participation, "digital heritage databases become less like artefacts and more like living resources - imbued with the strengths, struggles and stories of the past and linked to a vision of the future" (Gibson, 2008, p. 7).

The Storylines project, which uses the Ara Iritja platform, adheres to cultural protocols and "allows objects, people, places, stories, plants, animals and technology to be tagged and linked within the system to create vast knowledge profiles which reflect the many languages, stories and perspectives of Aboriginal Western Australia" (State Library of Western Australia, 2013). The table below details the functionalities and metadata used for one video in the collection. 
Table 1

Examples of Storylines Functionalities and Metadata: “North West Diary”

\begin{tabular}{|c|c|}
\hline $\begin{array}{l}\text { URL for one video } \\
\text { item in the } \\
\text { collection }\end{array}$ & $\begin{array}{l}\text { North West Diary } \\
\text { https://storylines.slwa.wa.gov.au/archive-store/view/10/5 }\end{array}$ \\
\hline $\begin{array}{l}\text { Video } \\
\text { Functionalities }\end{array}$ & $\begin{array}{l}\text { Play/pause, progress bar, and icon for full screen. } \\
\text { Identified people, places, and animals are listed with the time they } \\
\text { appear in the video. Users can click on the name and the video will open } \\
\text { at the correct time. }\end{array}$ \\
\hline File Type & Medium of original: VHS \\
\hline $\begin{array}{l}\text { Video metadata } \\
\text { fields }\end{array}$ & $\begin{array}{l}\text { Original Width, Original Height, Original File Size, Original Duration, } \\
\text { Original Name }\end{array}$ \\
\hline $\begin{array}{l}\text { Metadata fields } \\
\text { with links in the } \\
\text { values }\end{array}$ & None \\
\hline $\begin{array}{l}\text { Additional } \\
\text { metadata fields }\end{array}$ & $\begin{array}{l}\text { Stories, Archive number, Tags, Clip title, Date, Place, Creator, } \\
\text { Title, Collection, Medium of Original, Video Format of Original, Audio } \\
\text { Format of Original, Generation of Original, Duration of Original, } \\
\text { Publication Date, Production, Information \& Summary, References, } \\
\text { Location of Original, Original Reference, Alternative Formats }\end{array}$ \\
\hline $\begin{array}{l}\text { Traditional } \\
\text { Knowledge Labels }\end{array}$ & $\begin{array}{l}\text { Restrict text box allows users to request a record restriction based on } \\
\text { these reasons: sensitive, sorrow, or other.(See link below for } \\
\text { explanations) } \\
\text { https://www.keepingculture.com/in-depth/knowledge/ }\end{array}$ \\
\hline
\end{tabular}

Summary of some preliminary findings

- Digital Storytelling in Indigenous New Media Projects: Examples of Indigenous new media projects reveal how virtual spaces can act as extensions of physical ones and can reimagine oral traditions in new ways.

- Digital Storytelling in Indigenous Language Databases: There are many examples of digital technologies being used favorably for Indigenous language revitalization. Audio 
recordings, video, and text of songs and stories are enhanced with translations, dictionaries, pronunciation guides, and can include multiple dialects or language variants.

- Digital Storytelling in Existing Digital Platforms: At this time, more research needs to be done on the role of YouTube and social media interactions for Indigenous knowledge management.

\section{Conclusion}

Through this broad overview of Indigenous digital projects, it is clear that there is a diversity of Indigenous communities around the world who are experimenting with digital technologies for educational, social, cultural, and linguistic purposes. What is essential in all these projects is the emphasis on oral forms of expression and the inclusion of audio and video as means of communication. In this way, the ample opportunities offered by new technologies today provide for the increasingly favourable practice of digital storytelling for Indigenous communities. Developing user-friendly, culturally sensitive, non-commercial digital platforms is thus imperative. While there may already be existing commercial platforms like social media that serve these needs, issues of ownership, intellectual property, privacy, and lack of control still prevail (The Museum of Indian Arts and Culture, 2016, p. 2; Caspani, Brumana, Oreni, \& Previtali, 2017, p. 118). Therefore, it is important to continue funneling resources and dedicating efforts to creating user-friendly, accessible, and appropriate features that help maintain Indigenous traditions in the broader realm of knowledge management and communication technologies.

\section{References}

Acadia University. (2010). The Inuit Qaujimajatuqangit Adventure. http://www.inuitq.ca/index_en.html

Brown, P., Carpenter, J., Lawson, G., Lawson, K., Nathan, L.P., and Turin, M. (2017). Uplifting Voices. In Reflections of Canada: illuminating our opportunities and challenges at 150+ years. Peter Wall Institute for Advanced Studies, 264-269.

Burgess, J., Klaebe, H., \& McWilliam, K. (2010). Mediatisation and institutions of public memory: Digital storytelling and the apology. Australian Historical Studies, 41(2), 149-165. https://doi.org/10.1080/10314611003716861

Caspani, S., Brumana, R., Oreni, D., \& Previtali, M. (2017). Virtual museums as digital storytellers for dissemination of built environment: Possible narratives and outlooks for 
appealing and rich encounters with the past. International Archives of the Photogrammetry, Remote Sensing \& Spatial Information Sciences, Volume XLII-2/W5. Göttingen, Germany: Copernicus Publications.

Christen, K. (2011). Opening archives: Respectful repatriation. The American Archivist, 74(1), 185-210. http://digitalnais.org/wp-content/uploads/2013/09/Kimberly_Opening_Archives.pdf

Christen, K. (2015a). A safe keeping place: Mukurtu CMS innovating museum collaborations. In J. Decker (Ed.), Technology and digital Initiatives: Innovative approaches for museums (pp. 6168). Lanham, MD: Rowman \& Littlefield Publishers.

Christen, K. (2015b). Tribal archives, traditional knowledge, and local contexts: Why the "s" matters. Journal of Western Archives, 6(1), 1-19. https://digitalcommons.usu.edu/cgi/viewcontent.cgi?article=1046\&context=westernarchives

Cook, T. (2013). Evidence, memory, identity, and community: Four shifting archival paradigms. Archival Science, 13(2-3), 95-120. https://doi.org/10.1007/s10502-012-9180-7

Corntassel, J., Chaw-win-is, \& T'lakwadzi. (2009). Indigenous storytelling, truth-telling, and community approaches to reconciliation. ESC: English Studies in Canada, 35(1), 137-159. http://www.corntassel.net/IndigenousStorytelling\%202009.pdf

Cushman, E. (2013). Wampum, Sequoyan, and story: Decolonizing the digital archive. College English, 76(2), 115-135. http://digitalnais.org/wp-content/uploads/2013/09/CE0762Wampum.pdf

Edmonton Public Library. (2018). Voices of Amiskwaciy: Stories from Indigenous Edmonton. https://www.epl.ca/voices-of-amiskwaciy/

Flinn, A., Stevens, M., \& Shepherd, E. (2009). Whose memories, whose archives? Independent community archives, autonomy and the mainstream. Archival Science, 9(1-2), 71-86. https://link.springer.com/content/pdf/10.1007\%2Fs10502-009-9105-2.pdf

Gibson, J. (2008). People, place and community memory: Creating digital heritage databases in remote Aboriginal communities, presented at Initiatives, Ideas and Interaction: Sharing our Story, Alice Springs, 2007. Crows Nest, NSW: Australian Society of Archivists.

Ginsburg, F. (2016). Indigenous media from U-Matic to YouTube: Media sovereignty in the digital age. Sociologia \& Antropologia, 6(3), 581-599. http://dx.doi.org/10.1590/2238-

$\underline{38752016 v 632}$ 
Hamel, C., Benyoucef, M., \& Kuziemsky , C. (2012). Determinants of participation in an Inuit online community of practice. Knowledge Management Research \& Practice, 10(1), 41-54. https://doi.org/10.1057/kmrp.2011.15

Hopkins, C. (2006). Making things our own: The Indigenous aesthetic in digital storytelling. Leonardo, 39(4), 341-344. https://www.jstor.org/stable/20206265

Lambert, J. (2013). Digital storytelling: Capturing lives, creating community. Abingdon, United Kingdom: Routledge.

Lawrence, R. L. and Paige, D. S. (2016), What our ancestors knew: Teaching and learning through storytelling. New Directions for Adult and Continuing Education, 149, 63-72. https://doi.org/10.1002/ace.20177

Mukurtu CMS. (2015). Mukurtu mobile. http://mukurtu.org/mobile/

The Museum of Indian Arts and Culture. (2016). Indigenous Digital Archive: Building effective access to and collaboration with mass-digitized archival documents.

https://www.imls.gov/sites/default/files/lg-70-16-0047-16_proposal_documents.pdf

Nakata, N. M. (2007). Indigenous digital collections. Australian Academic \& Research Libraries, 38(2), 99-110. https://doi.org/10.1080/00048623.2007.10721280

Northern Territory Library. (2007). Mukurtu Wumpurrarni-kari Archive https://mukurtu.org/project/mukurtu-wumpurrarni-kari-archive/

O'Sullivan, S. (2013). Reversing the gaze: Considering Indigenous perspectives on museums, cultural representation and the equivocal digital remnant. In L. Ormond-Parker et al. (Eds.), Information technology and Indigenous communities (pp. 139-149). Canberra, ACT: AIATSIS Research Publications.

Ormond-Parker, L., \& Sloggett, R. (2012). Local archives and community collecting in the digital age. Archival Science, 12(2), 191-212. https://doi.org/10.1007/s10502-011-9154-1

Perley, D., O’Donnell, S., George, C., Beaton, B. \& Peter-Paul, S. (2016). Supporting Indigenous language and cultural resurgence with digital technologies. Fredericton: Mi'kmaq Wolastoqey Centre. University of New Brunswick, November. http://firstmile.ca/wpcontent/uploads/2016-Perley-Nov-Supporting-Indigenous-Language-Resurgence-with-DigitalTechnologies.pdf 
State Library of Western Australia. (2013). Storylines. https://www.slwa.wa.gov.au/explorediscover/indigenous-wa/storylines

Thomas, R. (2005). Honouring the oral traditions of my ancestors through storytelling. In L. Brown \& S. Strega (Eds.), Research as resistance: Critical, Indigenous and anti-oppressive approaches (pp. 237-254). Toronto: Canadian Scholars Press.

Thorner, S. (2010). Imagining an indigital interface: Ara Iritija indigenizes the technologies of knowledge management. Collections: A Journal for Museums and Archives Professionals, 6, 125-147. http://hdl.handle.net/10536/DRO/DU:30092021

University of New South Wales. (n.d.). Dharug and Dharawal Resources.

https://dharug.dalang.com.au/plugin_wiki/page/introduction

Washington State University's Center for Digital Scholarship and Curation. (2008). Plateau Peoples' Web Portal. https://plateauportal.libraries.wsu.edu/

Webb, D. (2015). Curating with community. http://library.ifla.org/1143/1/168-webb-en.pdf

Willox, A. C., Harper, S. L., Edge, V. L., 'My Word': Storytelling and method for preserving and promoting Indigenous oral wisdom, \& Rigolet Inuit Community Government. (2012).

Storytelling in a digital age: Digital storytelling as an emerging narrative method for preserving and promoting Indigenous oral wisdom. Qualitative Research, 13(2), 127-147. https://doi.org/ $10.1177 / 1468794112446105$

Withey, K. C. (2015). Sovereignty, repatriation, and the archival imagination. Collections: A Journal for Museum and Archives Professionals, 11(2), 115-138.

https://rowman.com/WebDocs/Withey\%2011.02.pdf 